Images du travail, travail des images

\title{
Demain un photographe va passer
}

\section{Thierry Dehesdin}

\section{(2) OpenEdition}

\section{Journals}

Édition électronique

URL : http://journals.openedition.org/itti/1144

DOI : 10.4000/itti. 1144

\section{Éditeur}

Université de Poitiers

\section{Référence électronique}

Thierry Dehesdin, « Demain un photographe va passer », Images du travail, travail des images [En ligne], 3 | 2017, mis en ligne le 01 février 2017, consulté le 14 avril 2021. URL : http:// journals.openedition.org/itti/1144; DOI : https://doi.org/10.4000/itti.1144

Ce document a été généré automatiquement le 14 avril 2021.

Images du travail, travail des images 


\title{
Demain un photographe va passer
}

\author{
Thierry Dehesdin
}

Image 1

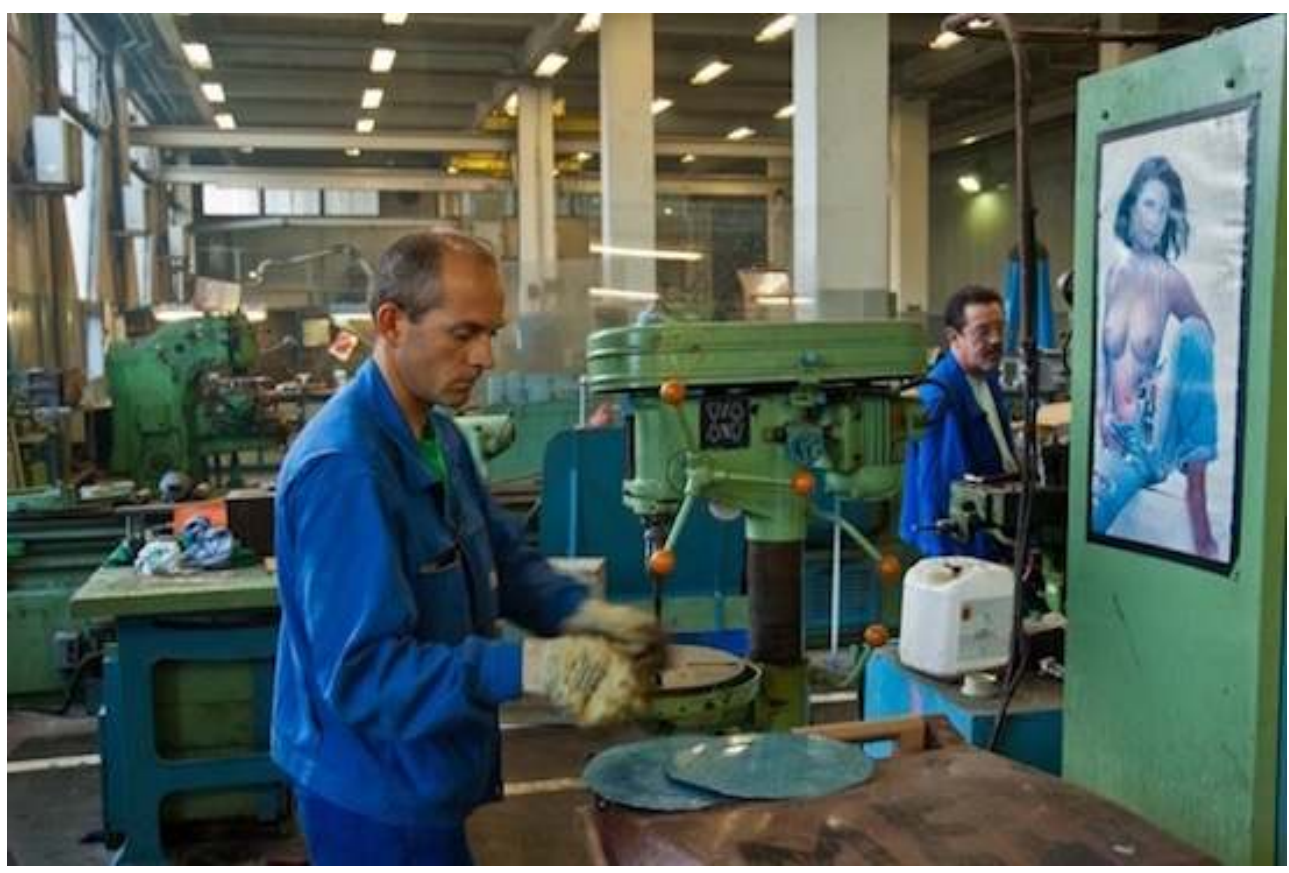

1 J'ai réalisé des photographies dans des usines, des bureaux et des supermarchés. C'est presque toujours en fonction de la relation que la personne entretient avec son travail qu'elle va accepter ou refuser d'être photographiée. Lorsque le refus est justifié par un physique supposé ingrat, ce n'est le plus souvent qu'un prétexte.

- À l'usine, les travailleurs acceptent presque toujours la photographie. Je n'ai eu qu'une seule fois des refus et c'était, explicitement, parce que ces ouvriers, ouvrières, avaient honte de leur travail déqualifié (le tri manuel des déchets recyclables) qu'ils ne voulaient pas être photographiés.

- À l'inverse, dans les supermarchés, les refus sont beaucoup plus nombreux. Si ma visite n'a pas été bien préparée en amont (l'encadrement a obtenu un accord de principe des salariés 
que je vais photographier), j'aurai du mal à trouver du personnel qui acceptera de se prêter au jeu. Les employés mettent en avant une photogénie supposée hasardeuse (" je ne suis pas bien en photo »), mais en réalité cela correspond à un refus d'être photographié en uniforme devant les rayons ou à une caisse enregistreuse. Je suis accompagné d'un chef (petit ou grand) et c'est difficile de donner la vraie raison de son refus. Je n'ai jamais de difficultés avec les cadres. Les émigrés récents sont généralement fiers d'être photographiés en uniforme sur leur lieu de travail et contents de pouvoir disposer de photos imprimées à envoyer à leurs proches.

- Dans les bureaux, j'essuie très rarement des refus. Dès lors que je photographie plusieurs personnes, ça peut même devenir un problème si certaines ne le sont pas. Être photographié, c'est aussi une forme de reconnaissance par l'entreprise. Le temps consacré à ranger son bureau pour la photo est presque plus important que celui consacré à se recoiffer et/ou se maquiller. Personne ne souhaite montrer son espace de travail tel qu'il est lorsque j'arrive, c'est-à-dire en désordre avec une bouteille d'eau, des emballages de friandises vides, des peluches, etc. Il y a ceux qui vont faire table rase, ceux qui vont tout aligner au cordeau et enfin ceux qui vont organiser un désordre savant de peur que l'on s'imagine qu'ils ne travaillent pas.

2 Cette photographie a été réalisée en 2004 à Issy les Moulineaux dans l'usine d'incinération d'ordure de la TIRU. Elle a été fermée en 2006 pour être remplacée par une nouvelle usine construite à quelques centaines de mètres. Les ouvriers savent qu'ils seront redéployés dans le groupe ou partiront en pré-retraite dans de bonnes conditions, mais ils acceptent mal cette fermeture. Leur usine n'a, à leurs yeux, pas démérité, dans la mesure où elle a toujours été transformée pour répondre aux nouvelles normes environnementales. J'ai été très bien accueilli parce qu'ils ont le sentiment que mes photos valorisent un travail et un lieu qui vont disparaître.

Ils (pas de femme dans cet atelier) me surveillent du coin de l'oeil parce qu'ils sont conscients du caractère politiquement incorrect de cet espace qu'ils se sont appropriés avec des calendriers de femmes nues. Ils surveillent mes réactions, un peu comme s'ils me faisaient une blague. J'ai réalisé depuis des photos dans la nouvelle usine qui est parfaitement aseptisée et où il n'y avait alors pas la moindre trace d'un quelconque calendrier, même des PTT.

4 J'ai mis en ligne un montage de certaines photos de la TIRU (sonorisé avec les bruits de l'usine).

\section{AUTEUR}

\section{THIERRY DEHESDIN}

Docteur en sociologie (3ème cycle), Thierry Dehesdin est photographe indépendant depuis 1981. Photographe de commande, il travaille pour des entreprises et des agences de publicité, en reportage comme en studio. Son travail personnel a été exposé à plusieurs reprises notamment au Musée Français de la Carte à Jouer. Il a également enseigné à l'école des Gobelins et à l'école de 
journalisme de Sciences-Po. Il a publié un livre consacré à La couleur en photographie aux éditions Pearson en 2011. Son prochain livre, Leçon de photographies (titre provisoire), est en préparation aux éditions Eyrolles. 